\title{
Attenuated familial adenomatous polyposis presenting as ampullary adenocarcinoma
}

\author{
J D Trimbath, C Griffin, K Romans, F M Giardiello
}

Gut 2003;52:903-904

The risk of periampullary cancer in patients with classic familial adenomatous polyposis (FAP) is significantly increased compared with the general population. However, the incidence of this extracolonic manifestation in attenuated FAP (AFAP) is unknown. We report the case of a 38 year old woman with no known family history of polyposis or colorectal cancer, who presented with ampullary adenocarcinoma. Diagnosis of AFAP was made only after evaluation of the patient's extended family history and genetic testing. This case report suggests that AFAP should be included in the differential diagnosis of patients with ampullary/duodenal tumours.

$\mathrm{S}$ mall bowel cancer is rare, with approximately 5300 new cases annually in the USA. ${ }^{1}$ However, the incidence of these neoplasms is increased in patients with familial adenomatous polyposis (FAP), hereditary non-polyposis colorectal cancer (HNPCC), and Peutz-Jeghers syndrome (PJS). ${ }^{2-4}$ Attenuated FAP (AFAP) is a variant of FAP in which ampullary cancer has not been reported as a presenting manifestation.

\section{CASE REPORT}

A 37 year old White woman in good health presented with sudden abdominal pain and anaemia and a diagnosis of acute pancreatitis was made. Workup for anaemia with colonoscopy revealed two polyps of unknown histology.

Eight weeks later the patient had recurrent acute epigastric pain. Again, acute pancreatitis was diagnosed. Endoscopic retrograde cholangiopancreatograpy revealed a $2 \mathrm{~cm}$ mass at the ampulla and histopathological review from surgical resection noted a villous adenoma with adenocarcinoma.

The patient's initial family history included a mother with seven adenomatous polyps at 70 years old and a maternal aunt who died of abdominal cancer at age 57 years. The young age of duodenal cancer and presence of colon polyps prompted an intensive investigation of the extended family history and construction of a four generation pedigree (fig l). This revealed an extensive family history of colorectal cancer and adenomatous polyposis, raising the suspicion of AFAP. APC

Abbreviations: FAP, familial adenomatous polyposis; HNPCC, hereditary non-polyposis colorectal cancer; PJS, Peutz-Jeghers syndrome; AFAP, attenuated familial adenomatous polyposis.

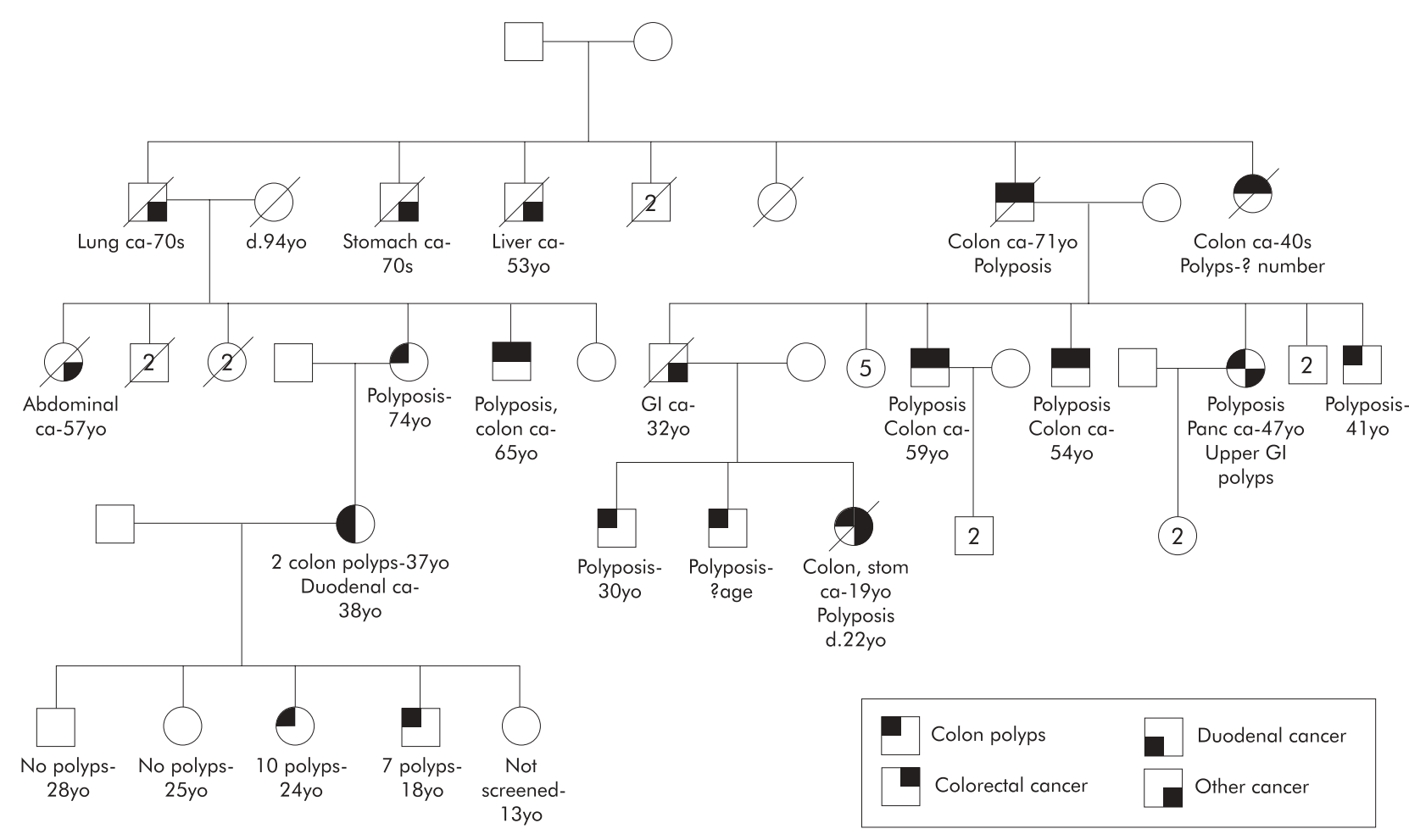

Figure 1 Extended family history following interviews, medical records collection, and endoscopic screening. 
gene testing was done, and the patient had a truncating mutation at the $3^{\prime}$ end of the APC gene in exon 15.

On screening colonoscopy of family members, the patient's mother, at age 74 years, had more than 100 adenomatous polyps. The patient's four eldest children underwent colonoscopy and two had multiple adenomas.

\section{DISCUSSION}

To our knowledge, this is the first case of AFAP presenting as ampullary cancer. First described in 1988, AFAP is characterised by $5^{\prime}$ and $3^{\prime}$ mutations of the APC gene, oligopolyposis (fewer than 100 adenomatous polyps) at presentation, marked phenotypic variation within pedigrees, and older age of colorectal cancer than FAP. ${ }^{5}$

In the general US population, ampullary cancer is rare, usually with an idiopathic aetiology, occurring in the seventh decade of life. Patients with Crohn's and coeliac disease have an increased risk of small bowel malignancy. Also, the hereditary conditions FAP, HNPCC, and PJS have an increased relative risk of small bowel adenocarcinoma. ${ }^{2-4}$ The relative risk of this tumour in AFAP has not been calculated; however, duodenal cancers have been reported in three patients from three separate families with this disorder.

Suspicion of a hereditary colorectal cancer syndrome in this case was raised by the young age of the patient at diagnosis of duodenal cancer, history of colorectal polyps at a young age, and the maternal history of seven colorectal adenomas. On extensive family history review, the concern for AFAP was heightened by the discovery of a heterogeneous pedigree phenotype (including relatives with either polyposis or oligopolyposis). Genetic testing of the APC gene confirmed that this patient was affected with AFAP.

\section{ACKNOWLEDGMENTS}

We are indebted to Ms Linda Welch for technical support. Supported in part by the Clayton Fund, the John G Rangos Sr Charitable Foundation, NIH grants CA 53801, P50 CA 62924, CA 93-16, and CA 78148

\section{(n)}

D Trimbath, Department of Medicine, the Johns Hopkins University School of Medicine, Baltimore, MD 21205, USA

C Griffin, Department of Pathology, and Sidney Kimmel Comprehensive Cancer Center, the Johns Hopkins University School of Medicine, Baltimore, MD 21205, USA

K Romans, Sidney Kimmel Comprehensive Cancer Center, the Johns Hopkins University School of Medicine, Baltimore, MD 21205, USA F M Giardiello, Departments of Medicine and Pathology, and Sidney Kimmel Comprehensive Cancer Center, the Johns Hopkins University School of Medicine, Baltimore, MD 21205, USA

Correspondence to: J D Trimbath, the Johns Hopkins Hospital, 550 North Broadway, Suite 108, Baltimore, MD 21205 , USA; jtrimba1@jhmi.edu

Accepted for publication 22 October 2002

\section{REFERENCES}

1 Cancer Facts and Figures. Atlanta, GA: American Cancer Society, 2002.

2 Offerhaus GJA, Giardiello FM, Krush AJ, et al. The risk of upper gastrointestinal cancer in familial adenomatous polyposis. Gastroenterology 1992;102:1980-2.

3 Watson $\mathbf{P}$, Lynch HT. Extracolonic cancer in hereditary nonpolyposis colorectal cancer. Cancer 1993:71:677-85.

4 Giardiello FM, Brensinger JD, Tersmette AC, et al. Very high risk of cancer in familial Peutz-Jeghers syndrome. Gastroenterology 2000; 119:1447-53.

5 Lynch HT, Smyrk T, Lanspa SJ, et al. Flat adenomas in a colon cancer-prone kindred. J Natl Cancer Inst 1998;80:278-82. 